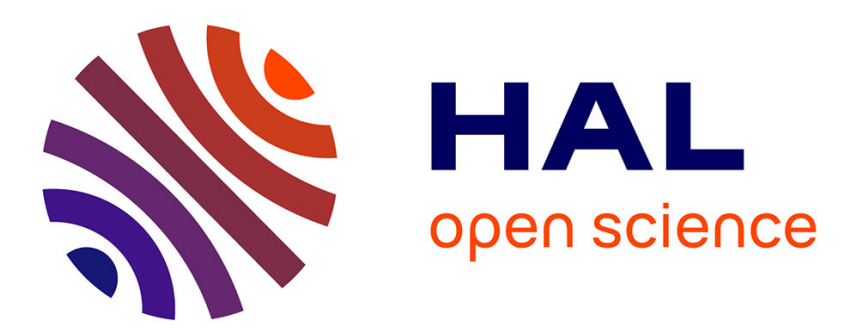

\title{
Ultrasound monitoring of the cure kinetics of an epoxy resin: Identification, frequency and temperature dependence
}

Nacef Ghodhbani, Pierre Maréchal, Hugues Duflo

\section{- To cite this version:}

Nacef Ghodhbani, Pierre Maréchal, Hugues Duflo. Ultrasound monitoring of the cure kinetics of an epoxy resin: Identification, frequency and temperature dependence. Polymer Testing, 2016, 56, pp.156-166. 10.1016/j.polymertesting.2016.10.009 . hal-01917107

\section{HAL Id: hal-01917107 \\ https://hal.science/hal-01917107}

Submitted on 22 Nov 2018

HAL is a multi-disciplinary open access archive for the deposit and dissemination of scientific research documents, whether they are published or not. The documents may come from teaching and research institutions in France or abroad, or from public or private research centers.
L'archive ouverte pluridisciplinaire $\mathbf{H A L}$, est destinée au dépôt et à la diffusion de documents scientifiques de niveau recherche, publiés ou non, émanant des établissements d'enseignement et de recherche français ou étrangers, des laboratoires publics ou privés. 
job_20181122092450_2018-11-22_-_Ultrasound_monitoring_of_the_cure_kinetics_of_an_epoxy_resin_-_Preprint.doc

\title{
Ultrasound monitoring of the cure kinetics of an epoxy resin: identification, frequency and temperature dependence
}

\author{
Nacef Ghodhbani, Pierre Maréchal*, Hugues Duflo \\ LOMC, UMR 6294 CNRS, Université du Havre, 75 rue Bellot, 76600 Le Havre. \\ Corresponding author: pierre.marechal@univ-lehavre.fr
}

\begin{abstract}
In this paper the monitoring of ultrasonic parameters of a thermosetting resin during an isothermal curing process is described. The ultrasonic properties are studied within the context of the monitoring of composite plate production by resin transfer molding (RTM). These ultrasonic characteristics can be related directly to cure kinetic models. An ultrasonic method, based on the measurement of the elastic constant and associated mechanical loss has been developed to identify the variations of the phase transformation. To study the reaction kinetics, the time dependence of the elastic coefficient is modeled using a Weibull distribution. The approximate time derivative form of this Weibull model makes it possible to find the relationship between ultrasonic parameters and the chemical Kamal model. The ultrasonic monitoring of a cooling process was also performed to study the temperature sensitivity after curing. Thanks to experimental measurements of the ultrasonic velocity and attenuation, the power law coefficient variations and their temperature sensitivity can be examined. The resulting viscoelastic Cole-Cole parameters were estimated and a frequency-temperature $(f, T)$ model was proposed.
\end{abstract}

Keywords:

ultrasound monitoring, thermosetting resins, Weibull distribution, cure kinetics. 
job_20181122092450_2018-11-22_-_Ultrasound_monitoring_of_the_cure_kinetics_of_an_epoxy_resin_-_Preprint.doc

\section{INTRODUCTION}

Organic matrix composites are materials composed of fibers, continuous or non-embedded, in a polymer matrix and may be either thermoplastic or thermosetting. In aeronautics, the most common is the carbon/epoxy composite used for its good mechanical strength and temperature resistance. The use of sensors to monitor the physical and mechanical properties during manufacture is a topical issue. Among various techniques of non-destructive testing and evaluation (NDT\&E), ultrasonic methods are used to measure velocity and attenuation of various materials. As an example, the relationships between grain distribution and attenuation $[1,2]$ have been investigated, the correlation between the viscoelastic properties and the volume fraction of porosity $[3,4,5]$ has been widely studied, or the on-line optimization and prediction of the final properties have been implemented on the resin transfer molding (RTM) process [6]. More precisely, the polymerization or cure monitoring has been investigated in the recent decades $[7,8,9,10,11,12,13]$, but few of these have related ultrasonic properties and chemical characteristics. Usual methods include differential scanning calorimetry (DSC) $[14,15,16,17,18]$, dynamic mechanical analysis (DMA) $[18,19,20]$ and dielectric analysis [20]. Thus, ultrasonic methods are suitable for industrial applications even if studies of the relationships between ultrasonic properties and chemical characteristics are still in progress. Lionetto [21] and McHugh [22, 23] have compared various wellassessed techniques (calorimetry, rheology, low frequency dynamic mechanical analysis) with ultrasonic methods. They demonstrated that the ultrasonic parameter variations can be related to the phase transformation (onset of cross-linking reaction, cure reaction rate, etc). This approach can be reinforced by a more specific study of the ultrasonic information. A modeling of the frequency dependence of the longitudinal ultrasonic wave attenuation in thermosetting resin makes it possible to identify viscoelastic parameters. In this context, Challis et al. $[24,25]$ have demonstrated that a Cole-Cole model successfully simulates wave propagation in cured resin. Relations between the attenuation power law and Cole-Cole parameters were developed and validated experimentally in a limited set of experiments at constant temperature of the viscous silicone oils [26, 27]. In this paper, a method is proposed to measure the ultrasonic characterization for the monitoring of thermosetting curing. Both time of flight and spectral methods are compared to determine the longitudinal wave velocity $c_{L}$ and attenuation $\alpha_{L}$ parameters. The variations of elastic constant $c_{33}$ and mechanical loss $\delta_{m}$ help to identify different stages of the cross-linking reaction. The influence of the set-point temperature on the ultrasonic parameters was investigated. The elastic constant $c_{33}$ was modeled with a Weibull distribution. The relation between the Kamal chemical model $[15,16]$ and an approximation of the Weibull model was developed [28]. To identify the influence of temperature after curing, a cured epoxy during a cooling process was monitored. The low-temperature sensitivity of the ultrasonic parameters was investigated, i.e. when the temperature is lower than the 
job_20181122092450_2018-11-22_-_Ultrasound_monitoring_of_the_cure_kinetics_of_an_epoxy_resin_-_Preprint.doc glass transition temperature $\left(T_{g}\right)$. The attenuation dispersion is modeled by a power law [26, 29, 30, 31, 32], which takes into account the attenuation sources related to the length of the polymer chains, similarly to the grain size in metals $[1,2]$. The temperature sensitivity of the power law parameters makes it possible to identify the temperature dependency of the ultrasonic velocity dispersion according to Szabo [31] and O'Donnell et al. [32] models. Moreover, the viscoelastic Cole-Cole parameters were estimated [26] as a function of the temperature. These models are compared in very good agreement with experimental spectral results and a frequency-temperature $(f, T)$ model [33] was developed for the ultrasonic parameters.

This paper is divided into three parts: the first describes the theoretical equations and the proposed experimental setup for the monitoring of an epoxy resin. The second part is focused on the isothermal cure monitoring results, variations in the mechanical properties during the polymerization and the model-fitting kinetics of isothermal cure. Lastly, the sensitivity of the ultrasonic parameters of a cured epoxy is monitored during a low velocity cooling.

\section{SETUP}

\section{A. Theory}

Cure monitoring is of primary interest for industrial applications such as the resin transfer molding (RTM) process. This topic [21] has led to various studies involving ultrasound and chemical reaction kinetics [34]. Compression properties along the propagation direction in the inspected materials can be identified thanks to the longitudinal waves. During a preliminary study the two first round-trip echoes in the epoxy resin were considered [28]. Nevertheless, this method is restricted in terms of longitudinal wave characteristics, due to the signal-to-noise ratio, i.e. high values of attenuation during the polymerization. As illustrated by Figure 1, an epoxy resin is monitored during its polymerization. This melt is introduced for inspection and monitoring between two blocks of aluminum, mimicking a mold. The spectrum $\underline{S}_{1}(f)$ corresponds to the first round-trip echo in aluminum only $s_{1}(t)$, whereas the spectrum $\underline{S}_{2}(f)$ corresponds to the first round-trip echo in aluminum and epoxy $s_{2}(t)$. These spectra are given by:

$$
\left\{\begin{array}{l}
\underline{S}_{1}(f)=\underline{S}_{0}(f) e^{-2 j \underline{k}_{A l u} d_{A l u}} \underline{R}_{E p o / A l u} \\
\underline{S}_{2}(f)=\underline{S}_{0}(f) e^{-2 j \underline{k}_{A l u} d_{A l u}} e^{-2 j \underline{k}_{E p o} d_{\text {Epo }}} \underline{T}_{\text {Alu/Epo }} \underline{R}_{A l u / E p o} \underline{T}_{E p o / A l u}
\end{array}\right.
$$

where $\underline{S}_{0}(f)$ is the emission signal, $\underline{k}_{A l u}=\omega / c_{A l u}(f)+j \alpha_{A l u}(f)$ and $\underline{k}_{E p o}=\omega / c_{E p o}(f)+j \alpha_{E p o}(f)$ are the complex longitudinal wavenumbers in aluminum and epoxy, respectively, $d_{A l u}$ and $d_{E p o}$ are the thicknesses of the aluminum block and epoxy layer, respectively, $\underline{R}_{E p o / A l u}$ is the complex reflection coefficient between the epoxy and aluminum layers, $\underline{T}_{E p o / A l u}$ is the complex transmission coefficient 
job_20181122092450_2018-11-22_-_Ultrasound_monitoring_of_the_cure_kinetics_of_an_epoxy_resin_-_Preprint.doc from the epoxy to the aluminum, and $\underline{T}_{A l u / E p o}$ is the complex transmission coefficient from the aluminum to the epoxy. Those transmission and reflection coefficients are theoretically complex and frequency dependent. Thus, the theoretical acoustic impedance is usually denoted as $\underline{Z}_{L}(f)=\rho . \underline{c}_{L}(f)$, where the complex longitudinal wave velocity includes losses, i.e. $\underline{c}_{L}(f)=c_{L}(f) \cdot\left(1+j \cdot \delta_{c}(f)\right)$, with $c_{L}(f)$ the frequency dependent longitudinal wave velocity and $\delta_{c}(f) \approx \alpha_{L}(f) \cdot c_{L}(f) / \omega$ the frequency dependent loss coefficient. In the context of this study, the longitudinal wave velocity dispersion does not exceed $0.1 \%$ and the loss coefficient is less than $2 \%$. Therefore, in the following, for practical aspects based on verified assumptions [26, 27], the longitudinal acoustic impedance is simply denoted as $Z_{L}=\rho . c_{L}$.

From the time response point of view, the longitudinal wave velocity in the epoxy layer $c_{E p o}$ and longitudinal attenuation $\alpha_{E p o}$ can be expressed as a function of the characteristics of the round-trip echoes , i.e. maximum amplitude ratio $\max \left(s_{2}\right) / \max \left(s_{1}\right)$, and delay $\Delta t$ between $s_{1}(t)$ and $s_{2}(t)$, respectively:

$$
\left\{\begin{array}{l}
c_{E p o}=\frac{2 d_{E p o}}{\Delta t} \\
\alpha_{E p o}=\frac{1}{2 d_{E p o}} \ln \left(\frac{\max \left(s_{2}\right)}{\max \left(s_{1}\right)} \frac{1}{T_{E A A E}}\right)
\end{array}\right.
$$

with $T_{E A A E}=T_{E p o / A l u} T_{A l u / E p o}=\frac{4 Z_{A l u} Z_{E p o}}{\left(Z_{A l u}+Z_{E p o}\right)^{2}}$, where $Z_{E p o}=\rho_{E p o} c_{E p o}$. and $Z_{A l u}=\rho_{A l u} c_{A l u}$.

The transfer function $\underline{T}(f)=\underline{S}_{2}(f) / \underline{S}_{1}(f)$ contains information on both longitudinal ultrasonic properties of the epoxy layer, i.e. longitudinal wave velocity $c_{E p o}(f)$ and longitudinal attenuation $\alpha_{E p o}(f)$. As a result, the transfer function argument $\operatorname{Arg}(\underline{T})$ and modulus $|\underline{T}(f)|$ give the following frequency dependencies:

$$
\left\{\begin{array}{l}
c_{E p o}(f)=\frac{4 \pi f d_{E p o}}{\operatorname{Arg}(\underline{T}(f))} \\
\alpha_{E p o}(f)=-\frac{1}{2 d_{E p o}} \ln \left(\frac{|\underline{T}(f)|}{T_{E A A E}}\right)
\end{array}\right.
$$




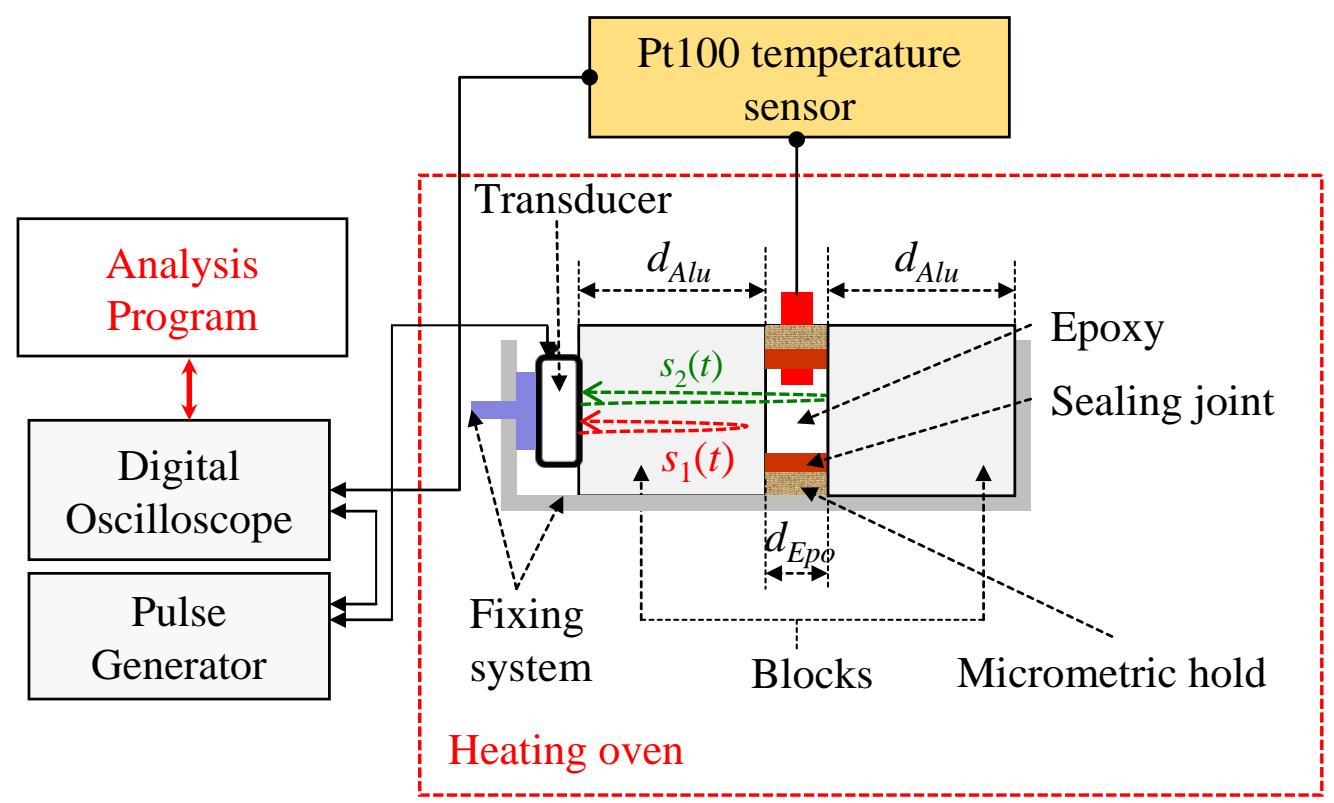

Figure 1: Experimental setup for the ultrasonic and temperature monitoring of the second layer between the two aluminum blocks.

\section{B. Experiment}

The experimental setup is made up of a contact transducer used successively as emitter and receiver (Olympus Panametrics $^{\circledR}$ ). Its center frequency is $f_{0}=5 \mathrm{MHz}$ and its bandwidth is $\Delta f_{6, r}=80 \%$. The transducer emits in a three layered Aluminum/Epoxy/Aluminum (Alu/Epo/Alu) structure, with thicknesses equal to $d_{A l u}=120 \mathrm{~mm}, d_{E p o}=7.6 \mathrm{~mm}, d_{A l u}=120 \mathrm{~mm}$, respectively (Figure 1 ). The two first round-trip echoes $s_{1}(t)$ and $s_{2}(t)$ are used to evaluate the ultrasonic properties of the second layer, i.e. the epoxy resin $\left(\operatorname{Resoltech}^{\circledR}\right)$ and its longitudinal wave velocity $c_{E p o}$ and longitudinal attenuation $\alpha_{E p o}$. The transducer is excited using a broadband impulse generator (Sofranel ${ }^{\circledR}$ ) and the echoes are acquired using a digital oscilloscope (Yokogawa ${ }^{\circledR}$ DL9140-5G/s 1GHz) on 125k points, with a sampling frequency $f_{s}=2.5 \mathrm{GHz}$ and averaged on $N_{a v}=1024$ acquisitions. These echoes are acquired automatically, with an acquisition period of 10 minutes. The temperature order is programmable and regulated by a heating oven (Kelviron ${ }^{\circledR}$ ). The epoxy resin melt $\left(\right.$ Resoltech $\left.^{\circledR}\right)$ is prepared by mixing the resin (Inclupox A) and the hardener (Inclupox B) in 100/45 mass proportions. The homogenization procedure consists in a melt during $2 \mathrm{~min}$, a degasing of $10 \mathrm{~min}$ using a void pump. This operation is repeated twice in order to remove the air incorporated during the melt. The aluminum blocks are greased to guarantee a straightforward unmolding. A sealing joint prevents the epoxy resin to flow out of the gap between the two aluminum blocks. The massive three-layered structure is thermostated in the heating oven before the epoxy resin is poured in the gap between the aluminum blocks. A Pt100 temperature sensor is immersed in the epoxy resin in order to record the exact temperature of the epoxy resin during the polymerization. 


\section{RESULTS}

\section{A. Isothermal cure}

\section{Time-of-flight characterization}

Figure 2 (left) shows the first two round-trip signals $s_{1}(t)$ and $s_{2}(t)$ during polymerization at a setpoint temperature $T=35^{\circ} \mathrm{C}$, in the aluminum (Alu) block only and the (Alu/Epo), respectively. Local temperature in resin is measured using a Pt100 sensor. Figure 2 (right) also shows the signals $s_{1}(t)$ and $s_{2}(t)$ at the beginning (right top) and the end (right bottom) of the reaction.
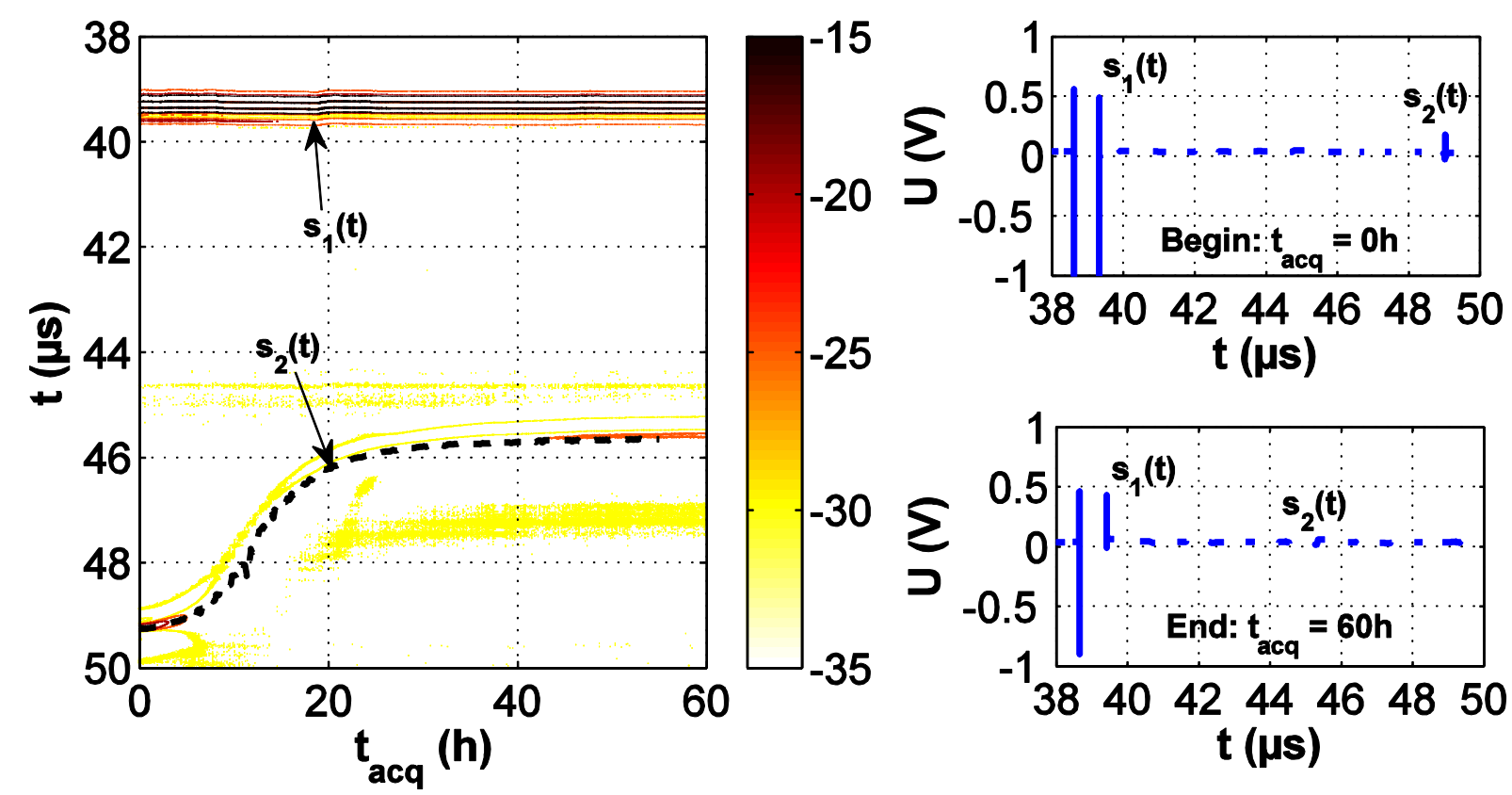

Figure 2: Round-trip echoes $s_{1}(t)$ and $s_{2}(t)$ in $\mathrm{dB}$ scale during polymerization at a setpoint temperature $T=35^{\circ} \mathrm{C}$, in the aluminum (Alu) block only and the (Alu/Epo), respectively (left). Round-trip echoes $s_{1}(t)$ and $s_{2}(t)$ at the beginning (right top) and the end (right bottom) of the polymerization at a setpoint temperature $T=35^{\circ} \mathrm{C}$.

The amplitude of the signal $s_{1}(t)$ reflected by the aluminum decreases slightly during polymerization. The amplitude of the first round-trip echo $s_{1}(t)$ is proportional to the reflection coefficient $R_{E p o / A l u}=\left(Z_{A l u}-Z_{E p o}\right) /\left(Z_{A l u}+Z_{E p o}\right)$ which decreases as the acoustic impedance of the epoxy resin $Z_{E p o}=\rho_{E p o} c_{L, E p o}$ increases during the polymerization. The delay corresponding to the second round-trip echo $s_{2}(t)$ is between $49 \mu \mathrm{s}$ and $45 \mu \mathrm{s}$, giving a variation of the ultrasonic velocity in the order of $1000 \mathrm{~m} / \mathrm{s}$ during the polymerization. For a period of polymerization $t_{a c q} \approx 13 \mathrm{~h}$ the amplitude of the signal $s_{2}(t)$ reaches its lower level, i.e. the attenuation is maximum. That corresponds to the phase transformation of the polymer. 
job_20181122092450_2018-11-22_-_Ultrasound_monitoring_of_the_cure_kinetics_of_an_epoxy_resin_-_Preprint.doc

The ultrasonic measurements can be related to the elastic properties, through the complex $\underline{c}_{33}$ viscoelastic coefficient which is the $(3,3)$ component of the viscoelastic $\left[\underline{c}_{i j}\right]$ matrix. This viscoelastic coefficient can be related to the ultrasonic longitudinal properties, i.e. $\underline{c}_{33}=\rho \cdot \underline{c}_{L}^{2}$, with $\rho$ the density and $\underline{c}_{L}=c_{L} \cdot\left(1+j \delta_{c}\right)$ the complex longitudinal velocity:

$$
\underline{c}_{33}=c_{33} \cdot\left(1+j \delta_{m}\right) \approx \rho c_{L}^{2} \cdot\left(1+j 2 \delta_{c}\right)
$$

where $c_{33} \approx \rho c_{L}^{2}$, and $\delta_{m} \approx 2 \alpha_{L} c_{L} / \omega$. This approximated expression is correct when the extent of attenuation $\alpha_{L}$ per wavelength $\lambda_{L}$ is small, i.e., $\alpha_{L} \lambda_{L} /(2 \pi)=\alpha_{L} c_{L} / \omega \approx 3.10^{-2}<<1$.

\section{Polymerization stages}

The mechanical property variations during the polymerization are illustrated by Figure 3 . The elastic constant $c_{33}(\mathrm{GPa})$ and mechanical loss $\delta_{m}(\%)$ are monitored during the polymerization versus the acquisition time $t_{a c q}(\mathrm{~h})$. From these curves, some typical parameters help to identify the different stages of the crosslinking reaction. Different stages can be identified using the tangent method: the liquid viscous stage (1), the glassy transition stage (2), the saturation solid stage (3). These stages are identified from the elastic constants. Two horizontal tangents are plotted from the start and the end of the monitoring. A third tangent is plotted at the inflexion point $\left(t_{i f x}\right)$, i.e. $\left(d c_{33} / d t_{a c q}\right)\left(t_{i f x}\right)=\left[d c_{33} / d t_{a c q}\right]_{\max }$. This latter intersects the two starting and ending horizontal tangents at the gelation $\left(t_{\text {gel }}\right)$ and saturation $\left(t_{\text {sat }}\right)$ times, respectively.

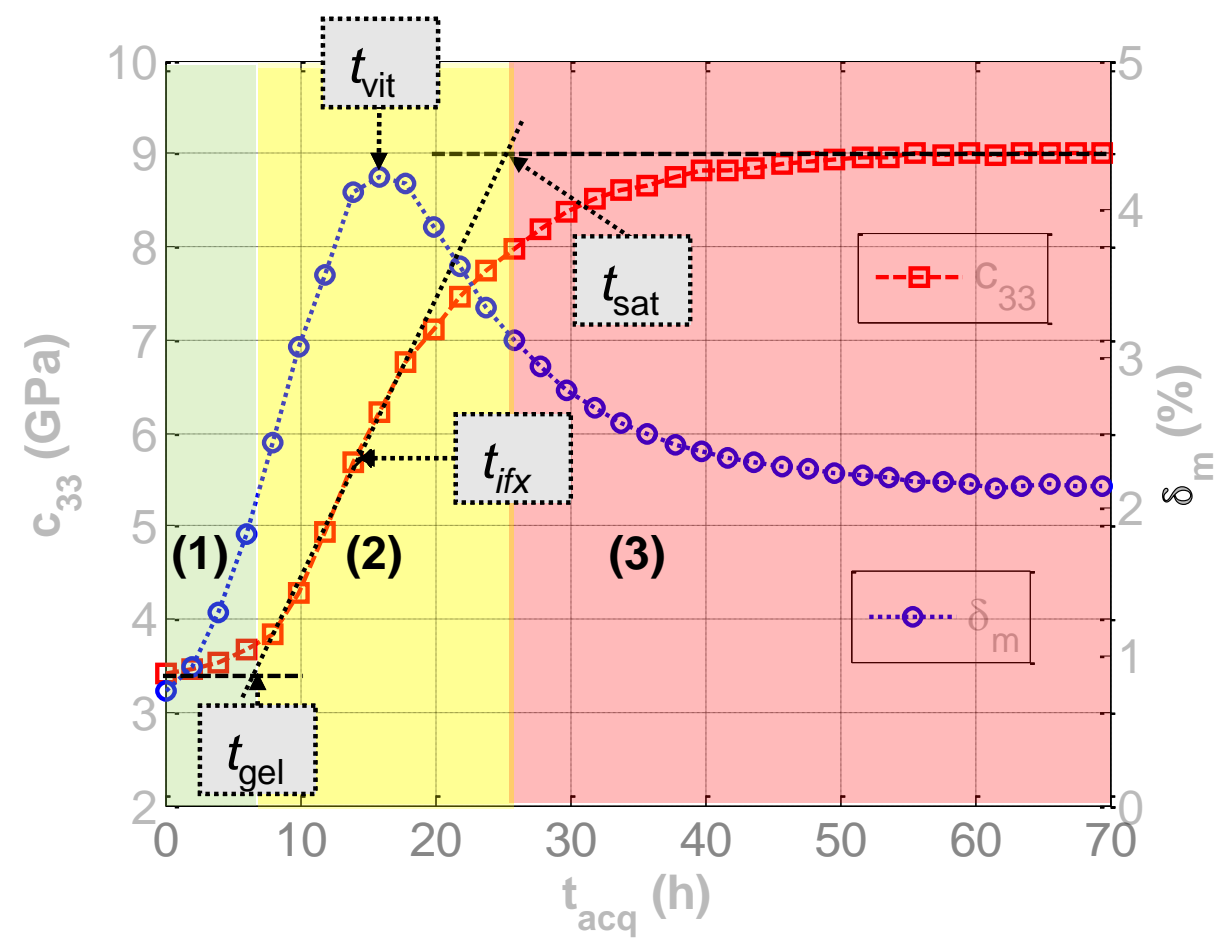

Figure 3: Evolution of the elastic properties as a function of time during the polymerization: elastic constant $c_{33}(\mathrm{GPa})$ $(\square)$ and mechanical loss $\delta_{m}(\%)(\bigcirc)$, at a setpoint temperature $T=35^{\circ} \mathrm{C}$. 
job_20181122092450_2018-11-22_-_Ultrasound_monitoring_of_the_cure_kinetics_of_an_epoxy_resin_-_Preprint.doc

As a result, the glassy solid time $\left(t_{g s}\right)$ is evaluated as the average of the gelation and saturation times $t_{g s}=\left(t_{g e l}+t_{s a t}\right) / 2$ on the wave velocity curves. Stage (1), from $t_{a c q}=0$ to $7 \mathrm{~h}$, is the liquid viscous state characterized by a slight increase of the elastic constant. Stage (2), from $t_{a c q}=7$ to $25 \mathrm{~h}$, is the glassy transition stage and can be decomposed in two parts. The gelation stage (2a) is characterized by the rapid increase in the elastic constant from the gelation time $\left(t_{g e l}\right)$ to the glassy solid time $\left(t_{g s}\right)$. In this zone, the crosslinking density increases greatly, with a reduction in the mobility of the chains of molecules. The vitrification stage (2b) is characterized by a decrease in the reaction kinetics, i.e. $\left[t_{g s} ; t_{s a t}\right]$. The saturation solid stage (3) starts at the saturation time $\left(t_{s a t}\right)$ and corresponds to the end of the polymerization, i.e. negligible polymerization kinetics. The mechanical loss peak occurring at the time $\left(t_{v i t}\right)$ nearly matches that of the inflexion point $\left(t_{i f x}\right)$ and that of the glassy solid time $\left(t_{g s}\right)$. In this vitrification transition zone, i.e. $t_{a c q} \in\left[t_{g e l} ; t_{s a t}\right]$, the vitrification reaches its maximum around $\left(t_{v i t}, t_{i f x}, t_{g s}\right)$, depending on the chosen definition. The increase in the overall elastic constant during the monitoring is around $5.5 \mathrm{GPa}$, indicating that the transition from viscous liquid to glassy solid results in significant changes in the elastic properties. This change can be related directly to the polymer concentration $P\left(t_{a c q}\right) \in\left[0 ; \alpha_{\text {max }}\right]$, defined by a law giving $P(0)=0$ and $P(\infty)=\alpha_{\text {max }}$.

$$
c_{33}\left(t_{a c q}\right)=c_{33,0}+\left(c_{33, \infty}-c_{33,0}\right) \cdot P\left(t_{a c q}\right)
$$

where $c_{33,0}$ and $c_{33, \infty}$ correspond to the elastic constants in the epoxy resin in the initial and final states, respectively.

\section{Setpoint temperature sensitivity}

The temperature sensitivity of the polymerization of the epoxy resin at a thermostated low temperature was investigated. The ultrasonic properties are monitored as a function of time, for three setpoint temperatures at $T=30^{\circ}, 35$, and $40^{\circ} \mathrm{C}$. The main effect that can be observed is that the reaction kinetics appear to increase with the setpoint temperature (Table 1):

Table 1: Experimental parameters obtained from $c_{33}$ at the setpoint temperatures $T=30,35$ and $40^{\circ} \mathrm{C}$.

\begin{tabular}{|c|c|c|c|c|c|}
\hline$T\left({ }^{\circ} \mathrm{C}\right)$ & $t_{v i t}(\mathrm{~h})$ & $t_{i f x}(\mathrm{~h})$ & $t_{g e l}(\mathrm{~h})$ & $t_{\text {sat }}(\mathrm{h})$ & $t_{g s}(\mathrm{~h})$ \\
\hline 30 & 15.9 & 17.9 & 9.54 & 31.1 & 20.3 \\
\hline 35 & 14.0 & 14.0 & 7.10 & 24.9 & 16.0 \\
\hline 40 & 9.94 & 9.94 & 5.38 & 19.9 & 12.6 \\
\hline \multicolumn{6}{|c|}{$\begin{array}{c}T\left({ }^{\circ} \mathrm{C}\right) \text { : thermostated setpoint temperature; } t_{v i t}(\mathrm{~h}) \text { : vitrification time; } \\
t_{i f x}(\mathrm{~h}) \text { : inflexion time; } t_{g e l}(\mathrm{~h}) \text { : gelation time; } t_{s a t}(\mathrm{~h}) \text { : saturation time; } \\
t_{g s}(\mathrm{~h}) \text { : glassy solid time. }\end{array}$} \\
\hline
\end{tabular}


job_20181122092450_2018-11-22_-_Ultrasound_monitoring_of_the_cure_kinetics_of_an_epoxy_resin_-_Preprint.doc This is illustrated both on the curves of the elastic constant $c_{33}$ (Figure 4 (a)) and mechanical loss $\delta_{m}$ (Figure 4 (b)). As a result (Table 1), the glassy solid time can be evaluated by the average of the gelation time and saturation time $t_{g s}=\left(t_{g e l}+t_{s a t}\right) / 2$ on the elastic constant curves (Figure 4 (a)) at 20.3, 16.0 and 12.6 for the three setpoint temperatures at $T=30,35$, and $40^{\circ} \mathrm{C}$, respectively. As a comparison, the glassy solid time $t_{v i t}$ is evaluated on the mechanical loss curves (Figure 4 (b)) at 15.9, 14.0 and 9.9 for the three setpoint temperatures at $T=30,35$, and $40^{\circ} \mathrm{C}$, respectively. These characterization results are in good agreement, even if slight differences can be observed.

\section{B. Interpretation}

\section{Model-fitting kinetics of isothermal cure}

A basic approach to the polymerization reaction consists in a first order differential equation describing the polymer concentration $P$. It involves a polymerization kinetic constant $k_{P}$, here noted as the classical time constant $\tau=1 / k_{P}$ :

$$
P\left(t_{a c q}\right)=1-e^{-\frac{t_{a c q}}{\tau}}
$$

Nevertheless, due to the complexity of the reaction and diffusion process, the variable $k_{P}$ is not constant $[22,35,36]$. When taken into account, these considerations lead to a variation of the corresponding time constant. Moreover, it is observed experimentally that the polymerization kinetic starts slowly $\left(\left[d c_{33} / d t_{a c q}\right]_{t_{a c q}=0} \approx 0\right)$, which translates the complex polymerization reactions and interactions [15, 16, 37, 38]. Various models were developed [22, 35, 36], but their numerous parameter inputs are not always convenient. A closer approach to the first order solution (equation (8)) leads to consider the complexity of reaction kinetics, using the Weibull distribution:

$$
P_{W}\left(t_{a c q}\right)=1-e^{-\left(\frac{t_{c c q}}{\lambda}\right)^{k}}
$$

i.e. $\quad c_{33, W}\left(t_{a c q}\right)=c_{33,0}+\left(c_{33, \infty}-c_{33,0}\right) \cdot\left(1-e^{-\left(\frac{t_{c c q}}{\lambda}\right)^{k}}\right)$

where $\lambda$ and $k$ are the Weibull distribution parameters, fitted to model the polymerization reaction, in accordance with the canonical solution to the first order differential equation.

The identification was performed with consideration to the half polymerization duration $t_{50}$, previously defined as $t_{50}=\lambda \cdot(\ln (2))^{1 / k}$, and a second identification point, i.e. $t_{95}=\lambda .3^{1 / k}$. It leads to $(\lambda, k)$ estimated Weibull parameters. These estimates are used as input parameters for the LMS fitting procedure. 


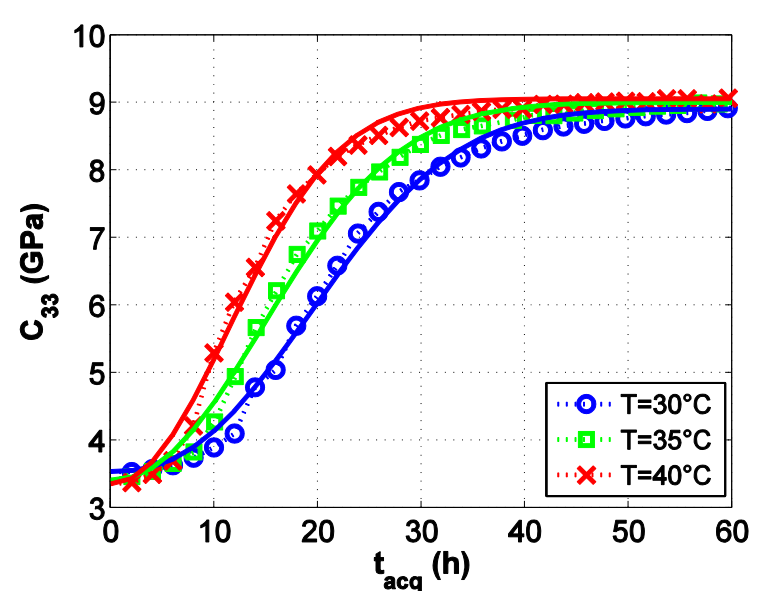

(a)

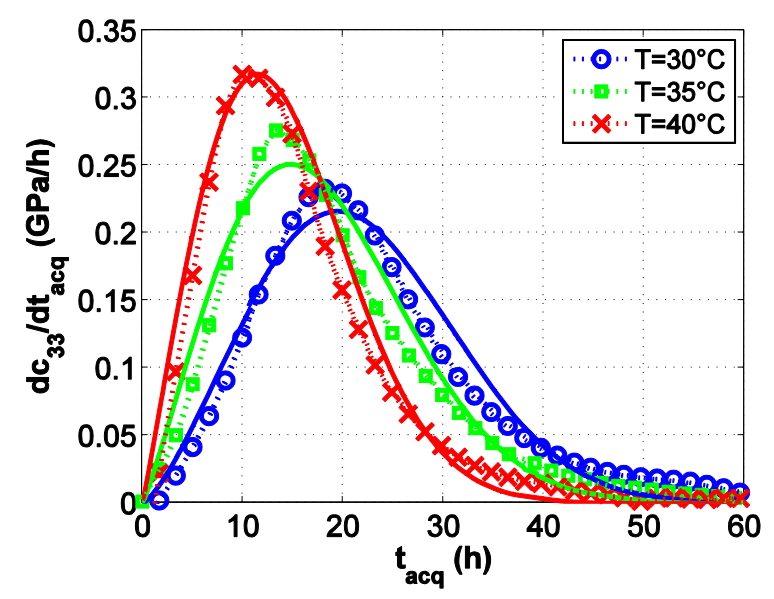

(c)

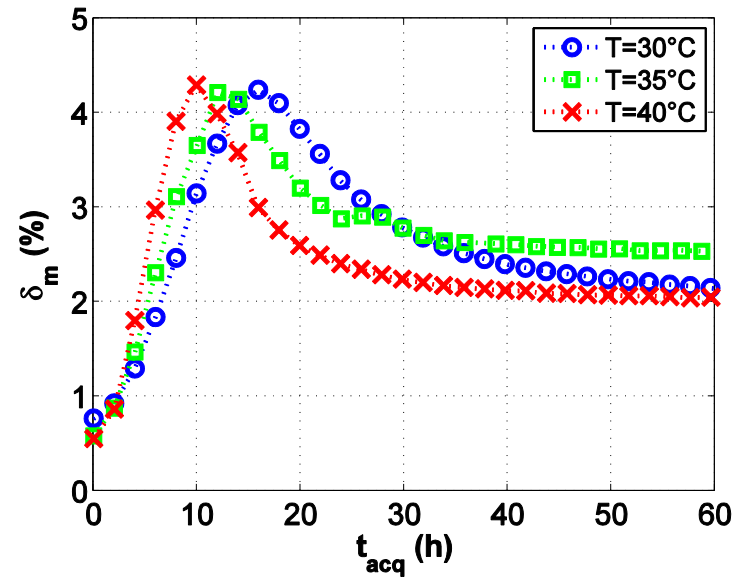

(b)

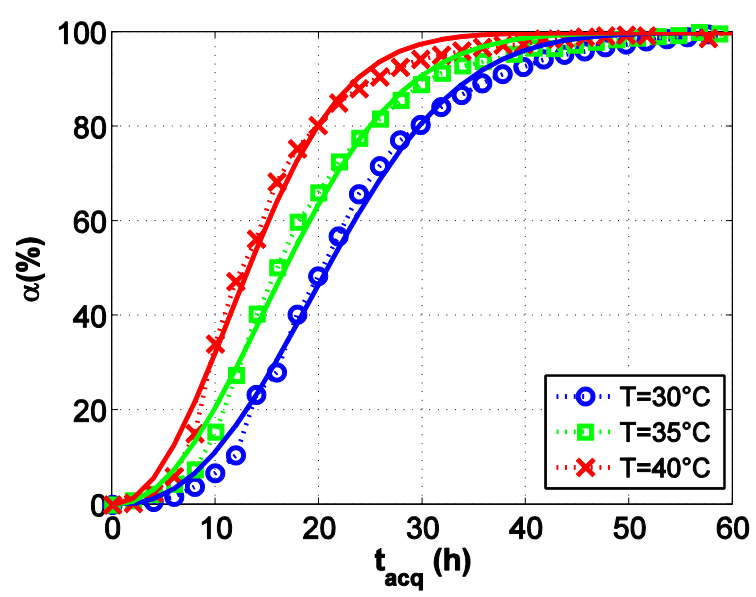

(d)

Figure 4: Evolution of the properties as a function of time $t_{a c q}(\mathrm{~h})$ during the polymerization. (a) elastic coefficient $c_{33}$ (GPa) and associated Weibull fit (solid lines), (b) mechanical loss $\delta_{m}(\%)$, (c) time derivative of the elastic coefficient $d c_{33} / d t_{a c q}(\mathrm{GPa} / \mathrm{h})$ and $(\mathrm{d})$ reaction conversion $\alpha(\%)$ at a setpoint temperature $T=30^{\circ} \mathrm{C}(\mathrm{O}), 35^{\circ} \mathrm{C}(\square)$ and $40^{\circ} \mathrm{C}(\mathrm{X})$.

Experimental results (dotted lines with markers) versus Weibull fit (solid lines).

Thus, an identification of the Weibull parameters obtained experimentally for the setpoint temperatures $T=30,35$ and $40^{\circ} \mathrm{C}$ (Figure 4 (a)) was done. The Weibull function (equation (7)) makes it possible to determine the analytical expressions of the inflexion time $t_{W, i f x}$, the gelation time $t_{W, g e l}$ and saturation time $t_{W, s a t}$ from the $(\lambda, k)$ Weibull parameters:

$$
\left\{\begin{array}{c}
t_{W, i f x}=\lambda\left(\frac{k-1}{k}\right)^{\frac{1}{k}} \\
t_{W, g e l}=t_{W, i f x}-\frac{P_{W}\left(t_{W, i f x}\right)}{P_{W}{ }^{\prime}\left(t_{W, i f x}\right)} \\
t_{W, s a t}=t_{W, i f x}+\frac{1-P_{W}\left(t_{W, i f x}\right)}{P_{W}{ }^{\prime}\left(t_{W, i f x}\right)}
\end{array}\right.
$$


job_20181122092450_2018-11-22_-_Ultrasound_monitoring_of_the_cure_kinetics_of_an_epoxy_resin_-_Preprint.doc where $P_{W}^{\prime}\left(t_{a c q}\right)$ is the time derivative of the Weibull function $P_{W}\left(t_{a c q}\right)$ (equation (7)). The numerical values of these characteristic parameters, i.e. the Weibull inflexion time $t_{W, i f x}$, the Weibull gelation time $t_{W, g e l}$, the Weibull saturation time $t_{W, s a t}$ (equation (9)) and Weibull glassy solid time $t_{W, g s}=\left(t_{W, g e l}+t_{W, \text { sat }}\right) / 2$ are summarized in Table 2 , and show a good agreement with experimental results in Table 1:

Table 2: Weibull parameters fitted from $c_{33}$ at the setpoint temperatures $T=30,35$ and $40^{\circ} \mathrm{C}$.

\begin{tabular}{ccccccc}
\hline$T\left({ }^{\circ} \mathrm{C}\right)$ & $\lambda(\mathrm{h})$ & $k$ & $t_{W, i f x}(\mathrm{~h})$ & $t_{W, g e l}(\mathrm{~h})$ & $t_{W, s a t}(\mathrm{~h})$ & $t_{W, g s}(\mathrm{~h})$ \\
\hline 30 & 24.3 & 2.38 & 19.3 & 8.31 & 33.3 & 20.8 \\
\hline 35 & 19.9 & 2.12 & 14.7 & 5.57 & 27.8 & 16.7 \\
\hline 40 & 15.7 & 2.06 & 11.4 & 4.15 & 22.1 & 13.1 \\
\hline
\end{tabular}

$T\left({ }^{\circ} \mathrm{C}\right)$ : thermostated setpoint temperature; $\lambda(\mathrm{h})$ : first Weibull parameter; $k$ : second Weibull parameter; $t_{W, i f x}(\mathrm{~h})$ : Weibull inflexion time; $t_{W, g e l}(\mathrm{~h})$ : Weibull gelation time; $t_{W, s a t}(\mathrm{~h})$ : Weibull saturation time; $t_{W, g s}(\mathrm{~h})$ : Weibull glassy solid time.

The experimental time derivative of the elastic coefficient $d c_{33} / d t_{a c q}$ and the corresponding Weibull fit $d c_{33, W} / d t_{a c q}$ (resulting from equation (8)) are compared in good agreement. As an illustration, Figure 4 (c) shows two properties that can be observed on the ultrasonic properties monitored for thermostated polymerization: the inflexion time $t_{i f x}$ and the value of the maximum $\left[d c_{33} / d t_{a c q}\right]_{\max }=\left[d c_{33} / d t_{a c q}\right]\left(t_{i f x}\right)$. This latter corresponds to the maximum slope of the elastic coefficient as a function of time $c_{33}\left(t_{a c q}\right)$, which is characteristic of the polymerization kinetics.

\section{Degree of reaction conversion}

The degree of reaction conversion $\alpha$ can be related to ultrasonic measurements, and to the polymer concentration $P$ model (equation (7)) through the elastic coefficient $c_{33}$ :

$$
\alpha\left(t_{a c q}\right)=\frac{c_{33}\left(t_{a c q}\right)-c_{33,0}}{c_{33, \infty}-c_{33,0}}
$$

where $c_{33,0}$ and $c_{33, \infty}$ are the minimum and the maximum values of this coefficient during the polymerization, respectively. As an illustration, the elastic coefficient $c_{33}$ (Figure 4 (a)) is calculated from the fitted Weibull model (equation (8)). The evolution of the reaction conversion during the polymerization (equation (10)) $\alpha\left(t_{a c q}\right)$ (Figure 4 (d)) is plotted for the setpoint temperatures $T=30$, 35 , and $40^{\circ} \mathrm{C}$. The evolution of the reaction rate during polymerization $d \alpha / d t_{a c q}$ allows us to identify experimentally the inflexion time $t_{i f x}=\{17.9,14.0,9.94\} \mathrm{h}$ decreasing with temperature, while the 
job_20181122092450_2018-11-22_-_Ultrasound_monitoring_of_the_cure_kinetics_of_an_epoxy_resin_-_Preprint.doc maximum reaction rate $\left[d \alpha / d t_{a c q}\right]_{\max }=\{4.25,4.65,5.43\} \% / \mathrm{h}$ increases with the setpoint temperatures $T=\{30,35,40\}{ }^{\circ} \mathrm{C}$. Curing reactions of epoxy resins are most frequently studied with a DSC technique in isothermal and/or non-isothermal modes. For isothermal cure, the fractional conversion of epoxy $\alpha$, is frequently modeled by the autocatalytic Kamal model [15, 16, 38]:

$$
\frac{d \alpha}{d t_{a c q}}=\left(k_{1}(T)+k_{2}(T) \alpha^{m}\right)(1-\alpha)^{n}
$$

In this model $k_{1}(T)$ is the non-autocatalytic rate constant corresponding to the initial reaction rate constant, $k_{2}(T)$ is the auto-catalytic reaction rate constant associated with the catalytic species formed during the cure, and $m$ and $n$ are the orders of the non-autocatalytic and autocatalytic reactions, respectively. Each rate constant $k_{i}(T)$ follows the Arrhenius equation:

$$
k_{i}(T)=A_{i} \cdot e^{-\frac{E_{a i}}{R T}}
$$

where $A_{i}$ is the pre-exponential factor, $E_{a i}$ is the activation energy and $R=8.314 \mathrm{~J} \cdot \mathrm{mol}^{-1} \cdot \mathrm{K}^{-1}$. In equation (11), the slope at the origin corresponds to $\left[d \alpha d d t_{a c q}\right]_{\alpha=0}=k_{1}$ (Table 3 ):

Table 3: Kinetic parameters for the setpoint temperatures $T=30,35$ and $40^{\circ} \mathrm{C}$.

\begin{tabular}{cccccccc} 
& \multicolumn{3}{c}{ Chemical model } & \multicolumn{3}{c}{ Approximated Weibull model } \\
\hline \multirow{2}{c}{$k_{1}\left({ }^{\circ} \mathrm{C}\right)$} & $\left.\mathrm{h}^{-1}\right)$ & $k_{2}\left(\mathrm{~h}^{-1}\right)$ & $m$ & $n$ & $k / \lambda$ & $(k-1) / k$ & $(k+1) /(2 k)$ \\
\hline 30 & 0.00138 & 0.0974 & 0.551 & 0.826 & 0.098 & 0.579 & 0.710 \\
\hline 35 & 0.00329 & 0.109 & 0.513 & 0.849 & 0.106 & 0.528 & 0.736 \\
\hline 40 & 0.00764 & 0.121 & 0.501 & 0.862 & 0.131 & 0.514 & 0.743 \\
\hline
\end{tabular}

$k_{1}\left(\mathrm{~h}^{-1}\right)$ : non-autocatalytic rate constant; $k_{2}\left(\mathrm{~h}^{-1}\right)$ : autocatalytic rate constant; $m$ : order of the nonautocatalytic reaction; $n$ : order of the autocatalytic reaction; $(k / \lambda)$ : approximated autocatalytic rate constant relative to the Weibull model; $(k-1) / k$ : order of the non-autocatalytic reaction relative to the Weibull model; $(k+1) /(2 k)$ : order of the autocatalytic reaction relative to the Weibull model.

This first rate constant $k_{1}$ is inserted into equation (11) and then $\left\{k_{2}, m, n\right\}$, are estimated using a least-squared procedure. As summarized in Table 3, the rate constant $k_{2}$ is much greater than $k_{1}$, indicating that the autocatalytic reaction is much faster than the non-autocatalytic reaction. As a result, the Kamal model can be approximated by:

$$
\frac{d \alpha}{d t_{a c q}} \approx k_{2}(T) \cdot \alpha^{m} \cdot(1-\alpha)^{n}
$$

This result can be compared to the Weibull model by developing the analytical expression of $d \alpha / d t_{a c q}$ versus $\alpha$ (equation (10)) as follows: 
job_20181122092450_2018-11-22_-_Ultrasound_monitoring_of_the_cure_kinetics_of_an_epoxy_resin_-_Preprint.doc

$$
\frac{d \alpha}{d t_{a c q}}=\left(\frac{k}{\lambda}\right) \cdot\left(\ln \left(\frac{1}{1-\alpha}\right)\right)^{\frac{k-1}{k}} \cdot(1-\alpha) \approx \begin{cases}\left(\frac{k}{\lambda}\right) \cdot \alpha^{\frac{k-1}{k}} \cdot(1-\alpha) & \text { at the first order } \\ \left(\frac{k}{\lambda}\right) \cdot \alpha^{\frac{k-1}{k}} \cdot(1-\alpha)^{\frac{k+1}{2 k}} & \text { at the second order }\end{cases}
$$

These two expressions are in good agreement, since the parameters are in the same order of magnitude. As an illustration, for $k=2$ and $\lambda=20$ we can approach the Kamal parameters $n \approx(k+1) /(2 k) \approx 3 / 4, \quad m \approx(k-1) / k \approx 1 / 2$ and $k_{2} \approx k / \lambda \approx 1 / 10$. The Arrhenius plots of $\ln \left(k_{i}\right)=\ln \left(A_{i}\right)-E_{a i} /(R T)$ versus $1 / T$ for $i=\{1,2\}$ are used to estimate the pre-exponential factors $A_{i}$ and the activation energies $E_{a i}$ (Table 4):

Table 4: Activation energies $E_{a i}$ and pre-exponent factor $A_{i}$ for autocatalytic and non-autocatalytic reaction.

\begin{tabular}{cccc}
\hline$E_{a 1}\left(\mathrm{~kJ} \cdot \mathrm{mol}^{-1}\right)$ & $E_{a 2}\left(\mathrm{~kJ}^{\mathrm{mol}}{ }^{-1}\right)$ & $A_{1}\left(\mathrm{~h}^{-1}\right)$ & $A_{2}\left(\mathrm{~h}^{-1}\right)$ \\
\hline 135 & 17.7 & $2.59 .10^{20}$ & 108 \\
\hline
\end{tabular}

The auto-catalytic activation energy $E_{a 1}$ is greater than the auto-catalytic activation energy $E_{a 2}$. The resulting identified pre-exponent factor of the auto-catalytic activation energy is much larger than the non auto-catalytic one $A_{1} \gg A_{2}$. The values $\left\{k_{1}, k_{2}, m, n\right\}$ are inserted in equation (11), and the $d \alpha / d t_{a c q}$ corresponding to the Kamal model (equation (11)) are compared to the time derivative of Weibull model (equation (10)) in Figure 5 (a). Clearly, the Weibull model predicted from ultrasonic experimental data is in accordance with the predicted Kamal model for each setpoint temperature $T=30,35$ and $40^{\circ} \mathrm{C}$. Nevertheless, even if they are in very good agreement, these models are formally different, the Kamal one (equation (11)) resulting from a chemical reaction kinetics approach, and the Weibull one (equation (14)) being an empirical approach. As illustrated by Figure 5 (b), the comparison between the approximated Kamal model (equation (13)) and the first order series development of the Weibull model (equation (14)), shows that the temperature tendencies are respected, but these approximations underestimate the time derivative of fractional conversion $d \alpha / d t_{a c q}$, relative to the exact Kamal and Weibull models. Moreover, these approximated models do not fit well with each other. Therefore, a further series development was performed, and the second order series development of the Weibull model shows (Figure 5 (c)) a very good agreement with the exact expression (equation (14)). As a result (Figure 5 (c)), the approximated Kamal model (equation (13)), which is formally identical to the second order series development of the Weibull model (equation (14)), can adequately describe the reaction kinetics, since the chosen sets of parameters for $\left\{k_{2}, m, n\right\}$ are those deduced from the second order approximation of the Weibull model, i.e. $\{k / \lambda,(k-1) / k,(k+1) /(2 k)\}$, as summarized in Table 3 . 


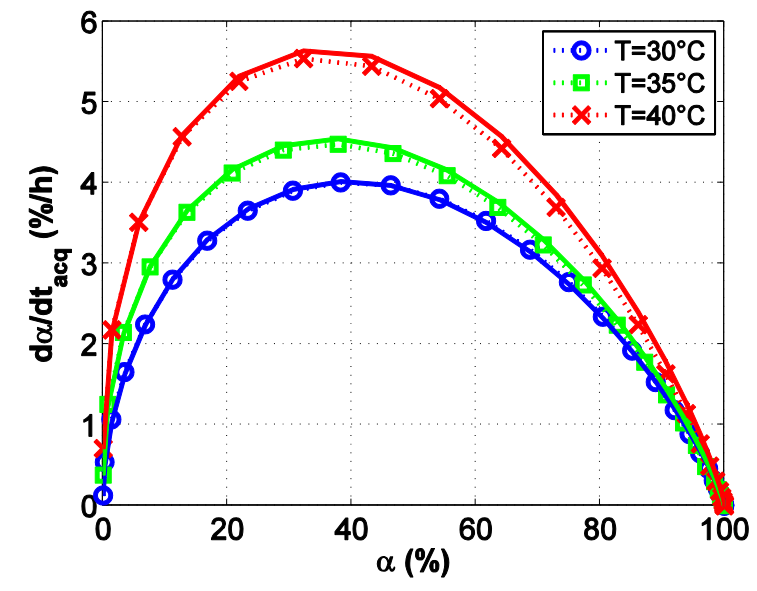

(a)

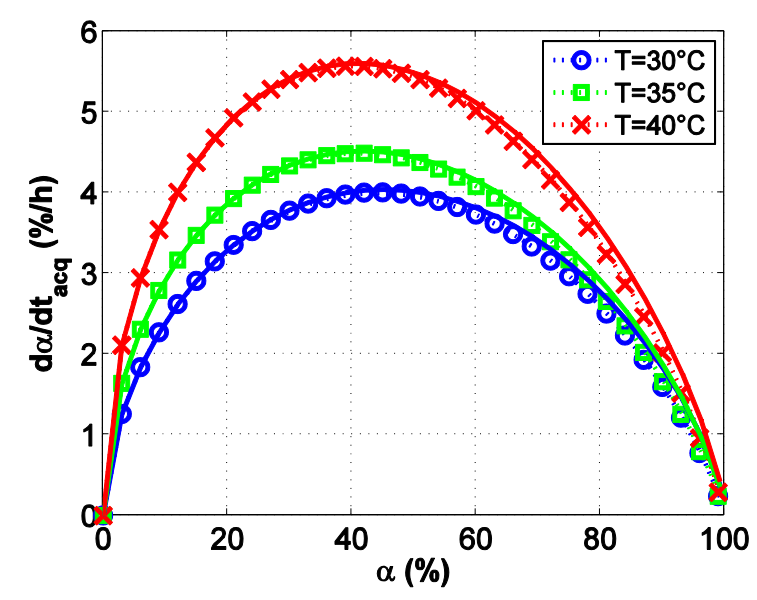

(c)

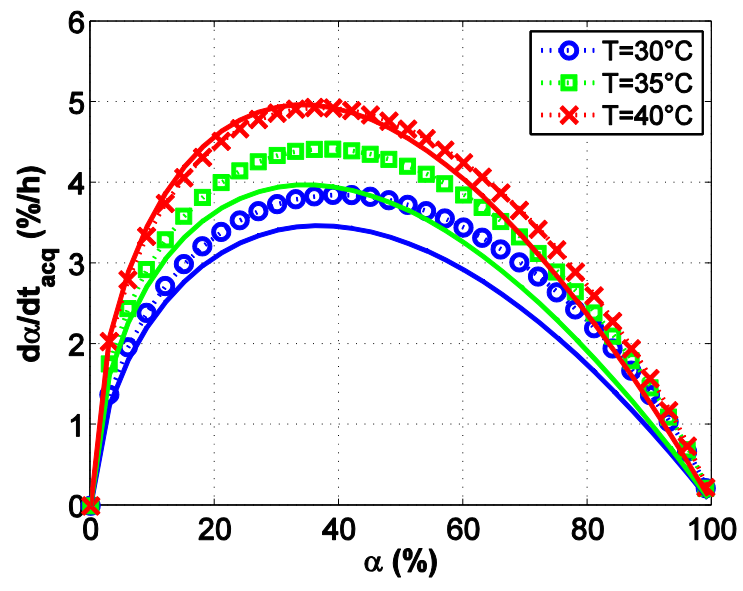

(b)

Figure 5: Comparison of $d \alpha / d t_{a c q}(\% / \mathrm{h})$ versus $\alpha(\%)$ according to the (a) Weibull (dotted lines with markers) model and fitted Kamal model (solid lines) ; (b) approximated Kamal model (solid lines, equation (13)) and first order series development of the Weibull model (dotted lines with markers, equation (14)); (c) exact Weibull model (dotted lines with markers, equation (14)) and second order series development of the Weibull model (solid, equation (14)).

These characterization results were carried out in a relatively low temperature range. It must be noticed that the isothermal temperature set $T=\{30,35,40\}{ }^{\circ} \mathrm{C}$ is lower than the glass transition temperature which was estimated around $T_{g} \approx 58^{\circ} \mathrm{C}$. The ultrasonic velocity was monitored during a low temperature polymerization process. The time dependence of the ultrasonic measurement of the elastic constant $c_{33}$ was identified to fit with a Weibull model. Moreover, a second order series development of the Weibull model was identified in very good agreement with the Kamal chemical model if the auto-catalytic activation energy parameter $k_{1}(T)$ is neglected. As a conclusion for the isothermal cure in the previously described context, the maximum value of the time derivative of the fractional conversion of epoxy $d \alpha / d t_{a c q}$ increases with temperature, i.e. it accelerates the chemical reaction kinetics. 


\section{Ultrasound characterization of cured epoxy}

To study the influence of temperature on the ultrasonic parameters, a cured epoxy during cooling was monitored. The sample was cured at a setpoint temperature $T=35^{\circ} \mathrm{C}$. The temperature was measured locally on the sample with variations from $46^{\circ} \mathrm{C}$ down to $28^{\circ} \mathrm{C}$. In this temperature range the cured epoxy is still in the glassy state, so the thermal factor alone can be studied. At a temperature higher than the glass transition temperature, the phase transformation is added to the thermal factor which makes our study more complicated.

\section{Time-of-flight characterization}

The change of ultrasonic velocity $c_{E p o}$ and attenuation $\alpha_{E p o}$ (Figure 6) as a function of the temperature is calculated by the time of flight method (equation (2)). This Figure 6 shows that ultrasonic velocity increases while temperature decreases. This negative temperature dependence was also observed in previous studies, such as viscous silicone oils [33] or [27]. At low temperature, when the epoxy is in the glassy state $\left(T \leq T_{g}\right)$, there is no movement of the polymer chain segments, and only vibrations and rotations of bonds can occur. In this area, the material has a strong glassy behavior as it is still rigid. If the temperature is increased and approaches the glass transition temperature $\left(T_{g}\right)$, the movements of sliding chains begin, the material becomes rubbery and less elastic, reducing the ultrasonic velocity. The dissipation is greater at high temperatures. This explains the increase in attenuation $\alpha_{\text {Epo }}$ (equation (2)) with temperatures (Figure 6).

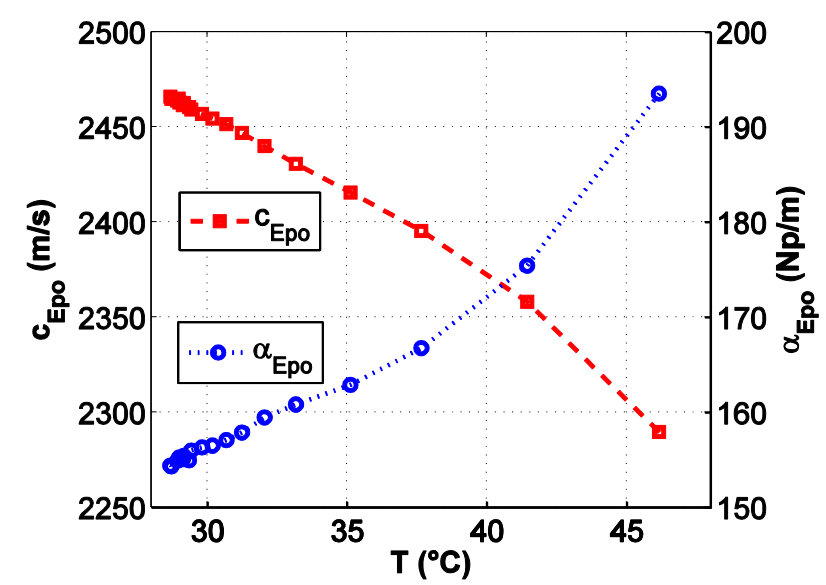

Figure 6: Temperature sensitivity of longitudinal wave velocity $c_{E p o}(\mathrm{~m} / \mathrm{s})$ and ultrasonic attenuation $\alpha_{E p o}(\mathrm{~Np} / \mathrm{m})$ (equation (2)). 
job_20181122092450_2018-11-22_-_Ultrasound_monitoring_of_the_cure_kinetics_of_an_epoxy_resin_-_Preprint.doc

\section{Frequency dependence characterization}

The signal processing of the round-trip echoes $s_{1}(t)$ and $s_{2}(t)$ shows the tendency of the ultrasonic parameters. Nevertheless, the spectral method makes it possible to extract the ultrasonic dispersion properties versus frequency. The complex spectra of useful roundtrip signals $s_{1}(t)$ and $s_{2}(t)$ are used to calculate the attenuation dispersion versus frequency $\alpha_{E p o}(f)$ (equation (3)). A first approach consists in considering the attenuation with a linear frequency dependence. Thus, the attenuation can be fitted by a linear law:

$$
\alpha_{E p o, l}(f)=\alpha_{a}\left(\frac{f}{f_{c}}\right)
$$

where $\alpha_{a}(\mathrm{~Np} / \mathrm{m})$ is the attenuation constant at $f_{c}(\mathrm{~Hz})$ which is the centroid frequency of the second echo $s_{2}(t)$. In a more accurate approach validated for a wide variety of materials [29, 30], the attenuation can be modeled on a finite bandwidth by a power law dependence as follows:

$$
\alpha_{E p o, p}(f)=\alpha_{0}\left(\frac{f}{f_{c}}\right)^{p}
$$

where $\alpha_{0}(\mathrm{~Np} / \mathrm{m})$ is the attenuation constant at $f_{c}(\mathrm{~Hz})$ and $1 \leq p \leq 2$ is a real positive number. In order to take into account viscoelastic parameters, the Cole-Cole model approximates the ultrasonic attenuation in the following form [26]:

$$
\alpha_{E p o, c}(f)=\frac{\eta_{0} \tau^{-2}}{2 \rho_{E p o} c_{E p o}^{3}} \sin \left(\beta \frac{\pi}{2}\right)\left(\frac{f}{f_{c}}\right)^{\beta+1}
$$

where $\eta_{0}$ (Pa.s) is the Newtonian dynamic viscosity at low frequency, $\tau$ is the relaxation time and $\beta$ (between 0 and 1) is an indicator factor of the width of the distribution of relaxation times. The approximate equation (17) is only valid if $\omega \tau \gg>1$ and assumes that $\tau=1 /\left(2 \pi f_{c}\right)$. From the identification of the equations (16) and (17) the relationship between the viscoelastic and ultrasonic parameters can be written as:

$$
\left\{\begin{array}{l}
\eta_{0}=\frac{2 \rho_{E p o} c_{E p o}^{3} \alpha_{0}}{\tau^{-2} \sin \left(\beta \frac{\pi}{2}\right)} \\
\beta=p-1
\end{array}\right.
$$

When analyzed in log scale, the linear law $\alpha_{E p o, l}(f)$ (equation (15)) shows adequate tendencies, but the accuracy of the modeling is quite resctricted. This led to consider an extended modeling using the power law fit $\alpha_{E p o, p}(f)$ (equation (16)). Therefore, the power law fit to the experimental measurements and the identified Cole-Cole model (equation (18)) are compared in Figure 7 (a). The comparison between the linear and power law models shows that the power law is more suitable than the linear model. The identified Cole-Cole model is able to take into account the change of 
job_20181122092450_2018-11-22_-_Ultrasound_monitoring_of_the_cure_kinetics_of_an_epoxy_resin_-_Preprint.doc temperature but within a restricted temperature range, i.e. $T=\{30,35,40\}{ }^{\circ} \mathrm{C}$. Indeed, the ColeCole model overestimates the attenuation for $T=44^{\circ} \mathrm{C}$. The power law parameters $\left(\alpha_{0}, f_{c}, p\right)$ sensitivity with temperature allows us to identify the ultrasonic velocity dispersion according to Szabo [31] which is compared with experimental spectral results and illustrated by Figure 7 (b).

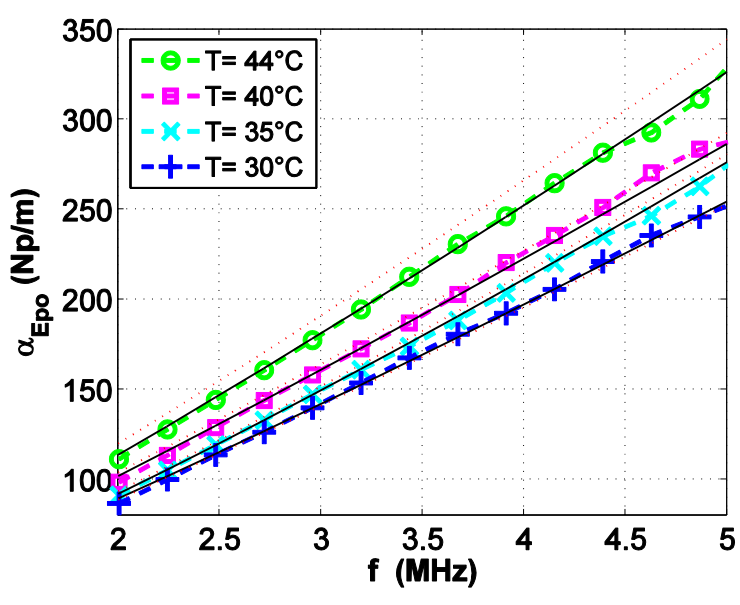

(a)

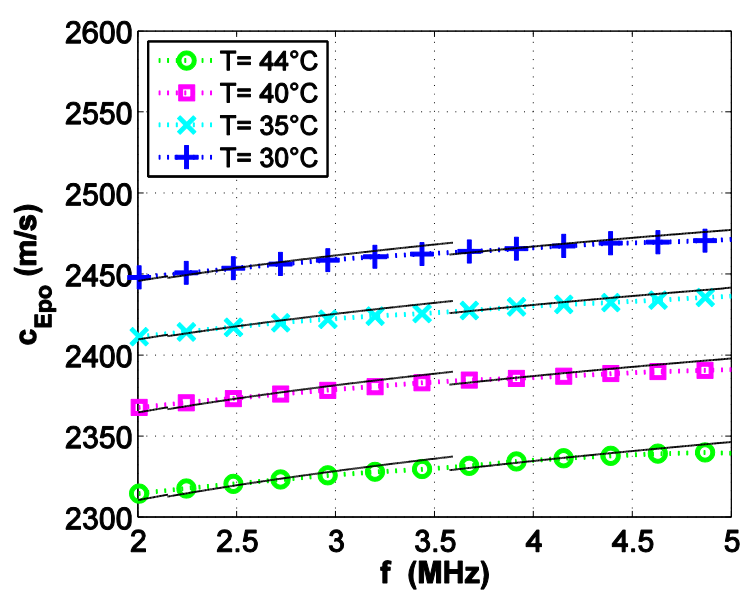

(b)

Figure 7: Frequency dispersion of the longitudinal (equation (3)) (a) attenuation $\alpha_{E p o}(f)$ (dashed lines with markers) and the associated power law fit (equation (16)) (solid line) and Cole-Cole model (equation (17) and (18)) (dotted line) and (b) wave velocity $c_{E p o}(f)$ (dashed lines with markers) compared with Szabo model [31] (solid line).

The variations of the ultrasonic parameters $\left(\alpha_{0}, f_{c}, p\right)$ and viscoelastic parameters $\left(\eta_{0}, \tau, \beta\right)$ as a function of the temperature are presented (Figure 8 (a), (b) and (c)). First, the temperature dependence of the centroid frequency $f_{c}$ (Figure $8(\mathrm{a})$ ) is calculated on the spectrum of the second echo $\underline{S}_{2}(f)$ (equation (1)). The relaxation time $\tau=1 /\left(2 \pi f_{c}\right)$ decreases with temperature when the material changes from the rubbery state to the glassy state (Figure 8 (a)). Second, the temperature dependence of the attenuation parameters $\left(\alpha_{0}, p\right)$ is based on the spectral method $\alpha_{E p o}(f)$ (equation (3)) fitted by the power law (equation (16)), and is illustrated by Figure 8 (b) and (c). As a result, at the beginning of the cooling, the temperature is $T \approx 46^{\circ} \mathrm{C}$ and the centroid frequency is $f_{c} \approx 2.98 \mathrm{MHz}$; at the end of the cooling, the temperature is $T \approx 28^{\circ} \mathrm{C}$ and the centroid frequency is $f_{c} \approx 3.16 \mathrm{MHz}$. The corresponding power parameters are $p \approx 1.10$ and 1.14 for $T \approx 46^{\circ} \mathrm{C}$ down to $28^{\circ} \mathrm{C}$. On the one hand, the centroid frequency $f_{c}$ and the power coefficient $p$ are weakly sensitive to the temperature, i.e. less than $5 \%$ variation for $T \in[28 ; 46]^{\circ} \mathrm{C}$. On the other hand, the attenuation coefficient $\alpha_{0}(\mathrm{~Np} / \mathrm{m})$ increases significantly with temperature, i.e. more than $35 \%$ variation for $T \in[28 ; 46]^{\circ} \mathrm{C}$. The temperature dependence of the $\left(\eta_{0}, \beta\right)$ Cole-Cole parameters are then deduced (equation (18)) and illustrated by Figure 8 (b) and (c). The attenuation coefficient $\alpha_{0}(\mathrm{~Np} / \mathrm{m})$ and 
job_20181122092450_2018-11-22_-_Ultrasound_monitoring_of_the_cure_kinetics_of_an_epoxy_resin_-_Preprint.doc dynamic viscosity $\eta_{0}$ (Pa.s) also increase with temperature, i.e. during the cooling, the dissipation and viscosity decrease when the epoxy passes from the rubbery to the glassy state.

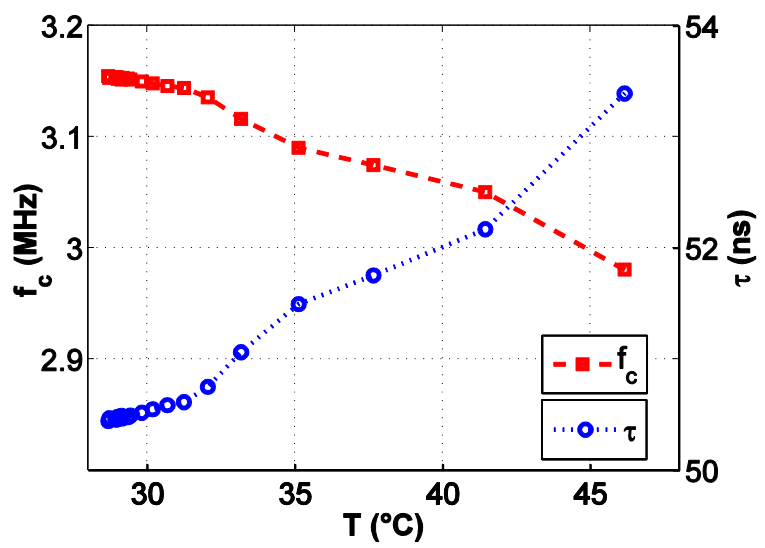

(a)

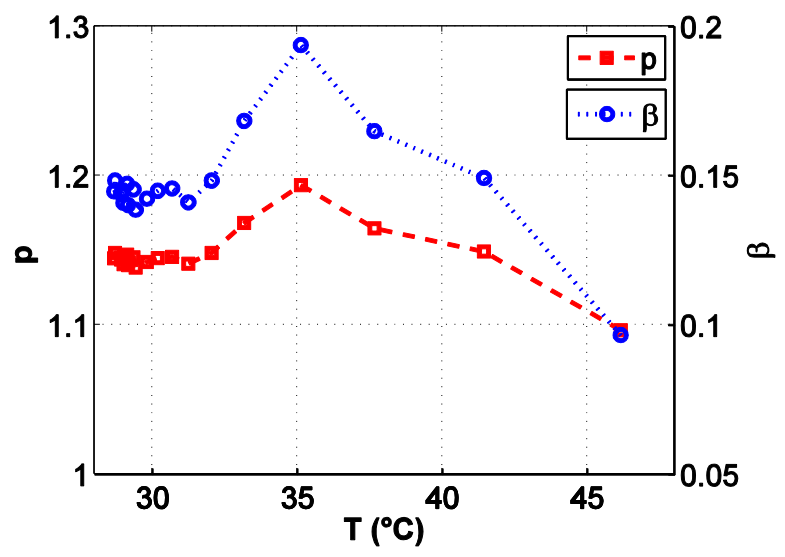

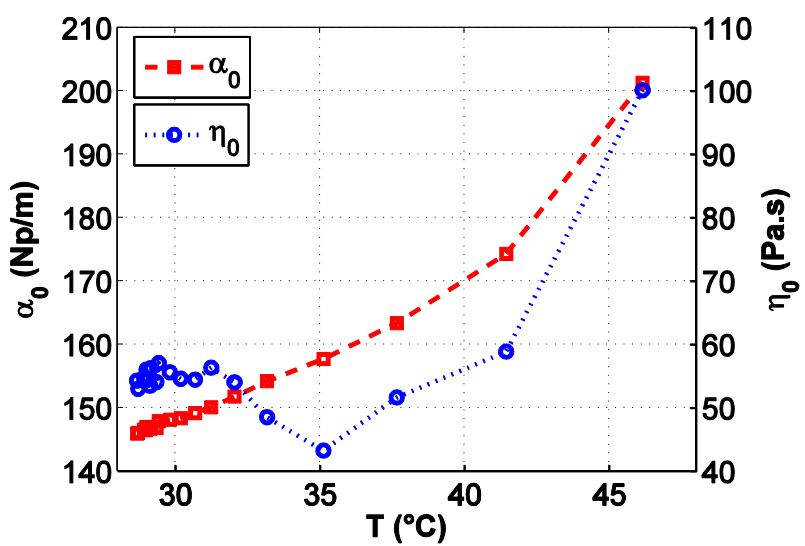

(b)

(c)

Figure 8: Temperature sensitivity of the (a) centroid frequency $f_{c}(\mathrm{MHz})$ and relaxation time $\tau(\mathrm{ns})$, (b) attenuation constant $\alpha_{0}(\mathrm{~Np} / \mathrm{m})$ and dynamic viscosity $\eta_{0}(\mathrm{~Pa} . \mathrm{s})$, (c) cofficients $p$ and $\beta$.

\section{Approximated frequency-temperature model}

Based on the experimental results, we can identify the $(f, T)$ dependence of $\left(\alpha_{E p o}, c_{E p o}\right)$ ultrasonic parameters in restricted frequency and temperature ranges, i.e. $f \in[2 ; 5] \mathrm{MHz}$ and $T \in[28 ; 46]^{\circ} \mathrm{C}$, respectively. A good approximation $\left(\alpha_{E p o, f, T}, c_{E p o, f, T}\right)$ is obtained if we consider the average values of the center frequency $f_{c} \approx 3.1 \mathrm{MHz}$ and power parameter $p \approx 1.15$. As a result, the attenuation depends on the frequency as a power law (equation (16)), and on the temperature as a quadratic law (equation (19)). In the same way, the velocity depends linearly on the frequency, and on the temperature as a quadratic law: 
job_20181122092450_2018-11-22_-_Ultrasound_monitoring_of_the_cure_kinetics_of_an_epoxy_resin_-_Preprint.doc

$$
\left\{\begin{array}{l}
\alpha_{E p o, f, T}(f, T)=\alpha_{0}\left(\frac{f}{f_{c}}\right)^{p}\left(1+a_{T, \alpha}\left(T-T_{r e f}\right)^{2}\right) \\
c_{E p o, f, T}(f, T)=c_{0}\left(1+a_{f, c}\left(f-f_{c}\right)\right)\left(1+b_{T, c}\left(T-T_{r e f}\right)+a_{T, c}\left(T-T_{r e f}\right)^{2}\right)
\end{array}\right.
$$

where $\alpha_{0}=148 \mathrm{~Np} / \mathrm{m}$ is the attenuation and $c_{0}=2460 \mathrm{~m} / \mathrm{s}$ is the ultrasonic speed at the reference temperature $T_{r e f}=30^{\circ} \mathrm{C}$. Using a LMS fitting procedure, the fitting coefficients are $a_{T, \alpha} \approx 1.45 .10^{-3}$, $a_{f, c} \approx 3.58 \cdot 10^{-9}, a_{T, c} \approx-7.4 \cdot 10^{-5}, b_{T, c} \approx-2.8 \cdot 10^{-3}$. As a result, the frequency and temperature dispersion maps of the velocity $c_{E p o}(f, T)$ (Figure 9 (a)) and attenuation $\alpha_{E p o}(f, T)$ (Figure 9 (b)) illustrate the fits defined in equation (19). The comparison between the experimental results and the $(f, T)$ model (equation (19)) is shown in Figure 9 (c) and (d). It is clear that the $(f, T)$ model is able to describe the variation of ultrasonic parameters in this temperature and frequency range.

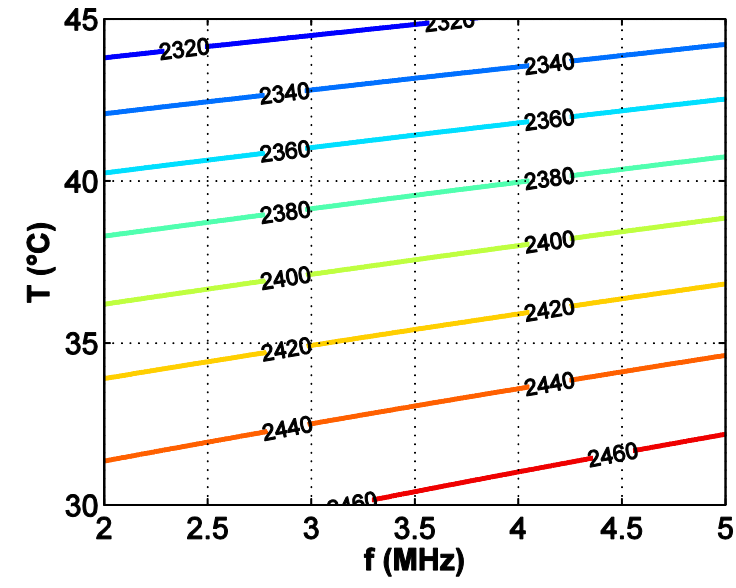

(a)

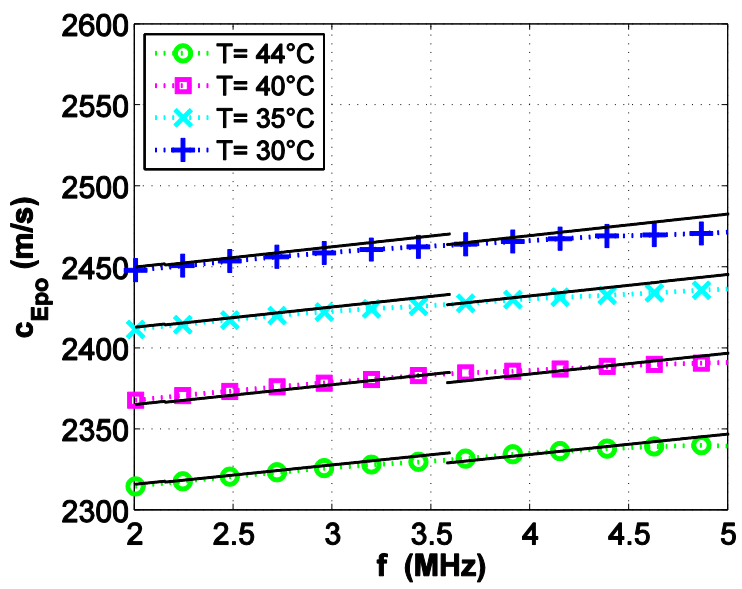

(c)

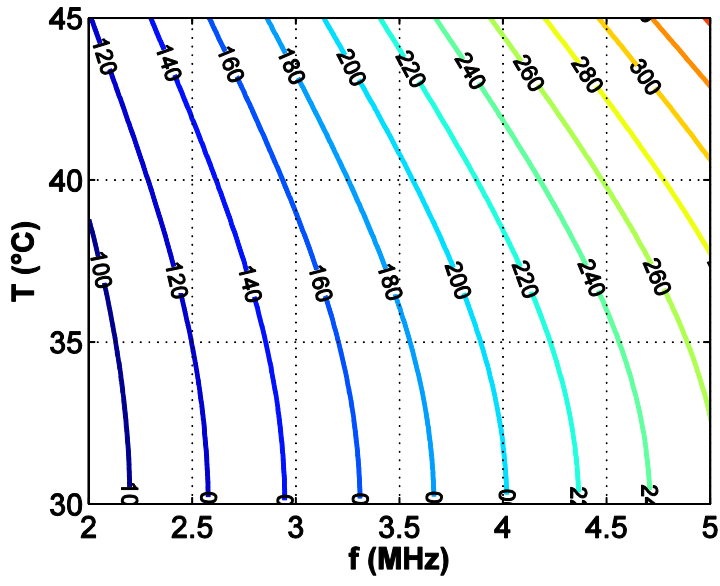

(b)

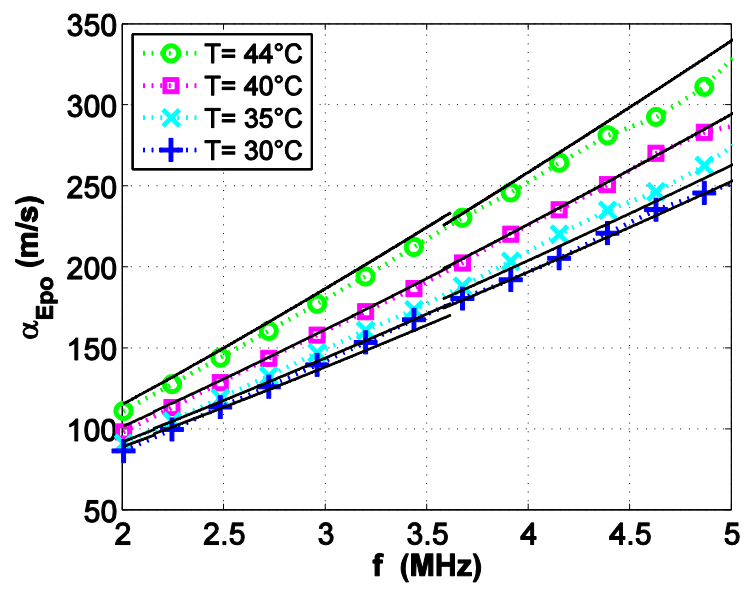

(d)

Figure 9: Frequency and temperature dispersion maps of the (a) velocity $c_{E p o, f, T}(f, T)$ and (b) attenuation $\alpha_{E p o, f, T}(f, T)$ (equation (19)). Comparison between experimental measurements (solid line) and the $(f, T)$ model (dashed line) for the (c) velocity $c_{E p o}(f)$ and (d) attenuation $\alpha_{E p o}(f)$, for $T=\{30,35,40,44\}{ }^{\circ} \mathrm{C}$. 


\section{CONCLUSION}

In the aim of achieving an accurate monitoring of thermosetting resin during an isothermal curing process, an experimental setup has been developed. The formulation of the ultrasonic characteristics, i.e. longitudinal wave velocity and attenuation, was adapted to this study. The ultrasonic characteristics of the cure kinetics are directly related to the elastic constant $c_{33}$ and mechanical loss $\delta_{m}$. Therefore, in order to improve the curing process, the phase transformation (liquid viscous stage, glassy transition stage and saturation solid stage) was monitored and studied. As a result, the time dependence of the elastic constant $c_{33}$ was modeled by a Weibull distribution, allowing the study of the reaction kinetics and the directly related degree of reaction conversion $\alpha$. The analytical form of the second order series development of the Weibull model was identified in very good agreement with the Kamal chemical model, in the case where the auto-catalytic activation energy parameter $k_{1}(T)$ is negligible. This analytical approach first makes it possible to link the ultrasonic properties $\left(c_{E p o}, \alpha_{E p o}\right)$ to the elastic properties $\left(c_{33}, \delta_{m}\right)$, leading to the identification of the phenomenological properties $\left(t_{\text {gel }}, t_{\text {vitr }}, t_{\text {satur }}\right)$. Then, the Weibull parameters $(k, \lambda)$ are fitted and related to the usual chemical parameters $\left(k_{2}(T), m, n\right)$.

In order to study the influence of the temperature after curing, the ultrasonic parameters were monitored during a cooling process. The frequency dispersion of the ultrasonic parameters was identified as a very sensitive indicator. The power law dispersion of the attenuation was identified as more suitable than the linear or Cole-Cole models. The attenuation power law parameter sensitivity to the temperature made it possible to identify the ultrasonic velocity dispersion according to Szabo. The Cole-Cole dispersion parameters were estimated through the power law parameters, thus identifying of the viscoelastic behavior. In the investigated area of frequency and temperature ranges, $f \in[2 ; 5] \mathrm{MHz}$ and $T \in[28 ; 46]^{\circ} \mathrm{C}$, an approximated analytic $(f, T)$ model was proposed and validated experimentally, both for the attenuation and velocity dependencies. 
job_20181122092450_2018-11-22_-_Ultrasound_monitoring_of_the_cure_kinetics_of_an_epoxy_resin_-_Preprint.doc

\section{ACKNOWLEDGMENTS}

The authors would like to thank the "Région Haute-Normandie" and the CNRS for their support to this work. Particular thanks are due to Naïm Samet, now NDT project manager Cetim, for fruitful preliminary works and discussions.

\section{COMPLIANCE WITH ETHICAL STANDARDS}

The authors declare that they have no conflict of interest.

\section{REFERENCES}

[1] Nicoletti D, Bilgutay N, Onaral B (1992) Power-law relationships between the dependence of ultrasonic attenuation on wavelength and the grain size distribution, J Acoust Soc Am 91:32783284

[2] Nicoletti D, Kasper D (1994) Ultrasonic attenuation based on the roney generalized theory and multiple power-law grain-size distributions, IEEE Trans Ultrason Ferroelect Freq Control 41:144-149

[3] Daniel I, Wooh S, Komsky I (1992) Quantitative porosity characterization of composite materials by means of ultrasonic attenuation measurements, J Nondest Eval 11:1-8

[4] Jeong H, Hsu D (1995) Experimental analysis of porosity-induced ultrasonic attenuation and velocity change in carbon composites, Ultrason. 33:195-203

[5] Pinfield VJ, Challis RE, Smith RA (2011) A comparison of stochastic and effective medium approaches to the backscattered signal from a porous layer in a solid matrix, J Acoust Soc Am $130: 122-134$

[6] Schmachtenberg E, zur Heide JS, Töpker J (2005) Application of ultrasonics for the process control of resin transfer moulding (RTM), Polymer Testing 24:330-338

[7] Papadakis EP (1974) Monitoring the moduli of polymers with ultrasound, J Appl Phys 45:1218-1222

[8] Lindrose A (1978) Ultrasonic wave and moduli changes in a curing epoxy resin, Exp Mech $18: 227-232$

[9] Rokhlin SI, Lewis DK, Graff KF, Adler L (1986) Real-time study of frequency dependence of attenuation and velocity of ultrasonic waves during the curing reaction of epoxy resin, $\mathrm{J}$ Acoust Soc Am 79:1786-1793

[10] Challis R, Alper T, Cocker R, Holmes A, White J (1991) Ultrasonic absorption and velocity dispersion measurements in thin adhesive layers, Ultrason 29:22-28 
job_20181122092450_2018-11-22_-_Ultrasound_monitoring_of_the_cure_kinetics_of_an_epoxy_resin_-_Preprint.doc

[11] Sidebottom D (1993) Ultrasonic measurements of an epoxy resin near its sol-gel transition, Phys Rev E 48:391-399

[12] Faiz B, Maze G, Decultot D, Moudden A, Aassif E, Ezzaidi M, (1999) Ultrasonic characterization of the quality of an epoxy resin polymerization, IEEE Trans Ultrason Ferroelect Freq Control 46:188-196

[13] Matsukawa M, Nagai I (1996) Ultrasonic characterization of a polymerizing epoxy resin with imbalanced stoichiometry, J Acoust Soc Am 99:2110-2115

[14] Prime RB (1973) Differential scanning calorimetry of the epoxy cure reaction, Polym Eng \& Sci 13:365-371

[15] Kamal MR (1974) Thermoset characterization for moldability analysis, Polym Eng \& Sci $14: 231-239$

[16] Sourour S, Kamal MR (1976) Differential scanning calorimetry of epoxy cure: isothermal cure kinetics, Thermochim. Acta 14:41-59

[17] Hardis R, Jessop JL, Peters FE, Kessler MR (2013) Cure kinetics characterization and monitoring of an epoxy resin using DSC, Raman spectroscopy, and DEA, Comp. Part A 49:100108

[18] White SR, Mather PT, Smith MJ (2002) Characterization of the cure-state of DGEBA-DDS epoxy using ultrasonic, dynamic mechanical, and thermal probes, Polym Eng \& Sci 42:51:67

[19] Goertzen W, Kessler M (2007) Dynamic mechanical analysis of carbon/epoxy composites for structural pipeline repair, Comp. Part B 38:1-9

[20] Lionetto F, Maffezzoli A (2005) Relaxations during the postcure of unsaturated polyester networks by ultrasonic wave propagation, dynamic mechanical analysis, and dielectric analysis, J Polym Sci Part B 43:596-602

[21] Lionetto F, Rizzo R, Luprano VAM, Maffezzoli A (2004) Phase transformations during the cure of unsaturated polyester resins, Mater Sci and Eng A 370:284-287

[22] Mc Hugh J (2008) Ultrasound technique for the dynamic mechanical analysis (DMA) of polymers, $\mathrm{PhD}$ thesis, Bundesanstalt für Materialforschung und -prüfung

[23] Mc Hugh J, Fideu P, Herrmann A, Stark W (2010) Determination and review of specific heat capacity measurements during isothermal cure of an epoxy using TM-DSC and standard DSC techniques, Polym Test 29:759-765

[24] Challis R, Blarel F, Unwin M, Paul J, Guo X (2009) Models of ultrasonic wave propagation in epoxy materials, IEEE Trans Ultrason Ferroelect Freq Control 56:1225-1237

[25] Challis RE, Blarel F, Unwin ME, Guo X (2011) On the modelling of ultrasonic bulk wave propagation in epoxies, J Phys: Conf Series 269:012001 
job_20181122092450_2018-11-22_-_Ultrasound_monitoring_of_the_cure_kinetics_of_an_epoxy_resin_-_Preprint.doc

[26] Ghodhbani N, Marechal P, Duflo H (2015) Ultrasonic broadband characterization of a viscous liquid: Methods and perturbation factors, Ultrason 56:308-317

[27] Samet N, Maréchal P, Duflo H (2012) Ultrasonic characterization of a fluid layer using a broadband transducer, Ultrason 52:427-434

[28] Samet N, Ndiaye EB, Marechal P, Duflo H (2013) Polymerization monitoring using ultrasound, in: www.ndt.net (Ed.), 13th Int. Symp. on Nondest. Charact. of Mater. (NDCM-XIII), www.ndt.net

[29] He P (1999) Experimental verification of models for determining dispersion from attenuation, IEEE Trans Ultrason Ferroelect Freq Control 46:706-714

[30] He P (1999) Direct measurement of ultrasonic dispersion using a broadband transmission technique, Ultrason 37:67-70

[31] Szabo T (1995) Causal theories and data for acoustic attenuation obeying a frequency power law, J Acoust Soc Am 97:14-24

[32] O’Donnell M, Jaynes E, Miller J (1981) Kramers-Kronig relationship between ultrasonic attenuation and phase velocity, J Acoust Soc Am 69:696-701

[33] Treeby B, Cox B, Zhang E, Patch S, Beard P (2009) Measurement of broadband temperature-dependent ultrasonic attenuation and dispersion using photoacoustics, IEEE Trans Ultrason Ferroelect Freq Control 56:1666-1676

[34] Naffakh M, Dumon M, Gerard JF (2006) Study of a reactive epoxy-amine resin enabling in situ dissolution of thermoplastic films during resin transfer moulding for toughening composites, Comp Sci and Tech 66:1376-1384

[35] Dimier F (2003) Reactive systems injection: kinetic and rheological laws determination and modelisation, Ph.D. thesis, Ecole Nationale Supérieure des Mines de Paris

[36] Paris C (2011) Analysis and modeling of the dynamic polymerization of thermosetting matrix composites, Ph.D. thesis, Université de Toulouse

[37] Lionetto F, Maffezzoli A (2013) Monitoring the cure state of thermosetting resins by ultrasound, Mater 6:3783-3804

[38] Wan J, Li C, Bu ZY, Xu CJ, Li BG, Fan H (2012) A comparative study of epoxy resin cured with a linear diamine and a branched polyamine, Chem Eng J 188:160-172 